\title{
Study on the Relationship between Economic Growth and Water Pollution in Jiangxi Province-Based on ARDL Model
}

\author{
Jun Yang, Youdong Wen* \\ School of Statistics, Jiangxi University of Finance and Economics, Nanchang, China \\ Email: *jxufewyd@163.com
}

How to cite this paper: Yang, J. and Wen, Y.D. (2018) Study on the Relationship between Economic Growth and Water Pollution in Jiangxi Province-Based on ARDL Model. Journal of Power and Energy Engineering, 6, 64-75. https://doi.org/10.4236/jpee.2018.67004

Received: July 13, 2018

Accepted: July 27, 2018

Published: July 30, 2018

Copyright (c) 2018 by authors and Scientific Research Publishing Inc. This work is licensed under the Creative Commons Attribution International License (CC BY 4.0).

http://creativecommons.org/licenses/by/4.0/

\section{(c) (i) Open Access}

\begin{abstract}
Identifying the key influencing factors of water pollution in Jiangxi Province is vital for formulating effective environmental protection measures. Jiangxi Province is located in the central of China. It plays a very important role in the "Rise of Central China" strategy. In recent years, water pollution in various regions of Jiangxi Province has become more and more serious. Therefore, exploring the main driving factors of water pollution in Jiangxi Province is of great practical significance. In this paper, the Autoregressive Distributed Lag (ARDL) approach is used to study the long-term equilibrium and short-term dynamic adjustment relationship between economic growth and water pollution in cities of Jiangxi Province from 1998 to 2016. The results show that there is a long-term equilibrium relationship between the water pollution index and the actual GDP of the first type of cities. However, due to the difference in the form and parameters of model, the inverted "U-shaped" relationship of the water pollution index and the actual GDP is not always presented. The regional economic growth of the second type of urban areas leads to increase of pollutants. It is obvious that the deteriorating environment has increased people's living costs and inhibited economic growth. The contradiction between economic development and environmental pollution in the third type of urban areas is most acute. Therefore, in order to effectively protect the environment, local governments should consider all these factors as well as regional heterogeneity in formulating policies.
\end{abstract}

\section{Keywords}

Cointegration Test, ARDL Model, Water Pollution

\section{Introduction}

The environment provides the necessary material conditions for the survival and 
development of our human beings and is the basic prerequisite for the survival and development of human society [1]. Since the 1990s, with the implementation of reform and opening up, China's economic development has gained great vitality. In 2017, China's nominal GDP reached 82.7 trillion yuan, ranking second in the world. However, along with the rapid economic growth, China's environmental pollution problem is also becoming more and more serious. The discharge of waste water, waste residue and waste gas has increased year by year. In 2014, China's wastewater discharge volume ranked first in the world, posing a huge threat to the survival and development of human beings. Therefore, it is important to understand and master the influencing factors of water pollution.

Compared with the eastern coastal provinces, the economic development of Jiangxi Province is relatively slow due to the geographical location. However, Jiangxi Province has achieved rapid growth in regional GDP as a result of positively responding to the country's "Rise of Central China" strategy in recent years. In 2016, the total production value of Jiangxi Province reached 1849.9 billion yuan, an increase of $9 \%$ over the previous year. The development of the tertiary industry is one of the important indicators to measure the development level of a country or region [2]. Since 1998, the proportion of the primary industry in Jiangxi Province has been declining; while the secondary industry has been as high as $54.7 \%$, but it has fallen back in the past two years, basically stable at around $45 \%$. The proportion of the tertiary industry has been rising, reaching $46.4 \%$ in 2011. In 2016, the proportion of the three industries in Jiangxi Province was 10.3:47.7:39. It can be seen that the level of economic development in Jiangxi Province has been significantly improved. However, with the continuous improvement of the aggregate economic level, the discharge of industrial wastewater has also been rising in 2000 . The emissions were 42.83 million tons, and it rose to 85.527 million tons in 2016, with an average annual growth rate of $4.5 \%$. Therefore, in order to cope with the increasingly severe environmental challenges, it is necessary to pay attention to water environment pollution in different regions in order to formulate effective environmental protection policies.

The remaining parts of this paper are organized as follows. The second part briefly reviews the related literature on economic growth and water pollution. The third part introduces the Autoregressive Distribution Lag model and sample data. The fourth part presents and discusses the result of empirical results. Conclusions are provided in the fifth part.

\section{Literature Review}

The most famous study on the relationship between economic growth and environmental pollution is the hypothesis of the Environmental Kuznets Curve (EKC) hypothesis. Grossman and Krueger (1991) found that in the early 1990s, there was a similar inverted U-type relationship between per capita income levels and emissions of most pollutants; that is, the environmental quality deteriorated first and then improved which along with accumulation of the economic 
growth [3]. In 1996, Panayotou borrowed the inverted U-shaped curve between per capita income and income inequality defined by Kuznets. For the first time, the relationship between environmental quality and per capita income was called the Environmental Kuznets Curve (EKC). The curve shows that when a country's economic development level is low, the degree of environmental pollution is relatively light, but with the increase of per capita income, the degree of environmental pollution is higher, that is, the degree of environmental pollution increases with the growth of the economy; After a certain level, there will be a certain "inflection point". The degree of environmental pollution is gradually decreased, that is, with the further increase of per capital income, and the environmental quality has been improved to some extent [4].

Many scholars used time series data to test EKC hypotheses in different countries, such as Dijkgraaf and Vollebergh (2005), which studied the income levels and environmental degradation of individual OECD countries [5]. With the improvement of time series analysis technology, the focus of researchers has turned to co-integration analysis and causal analysis of the EKC hypothesis. Egli (2004) argued that the impact of short-term and long-term economic growth on environmental degradation is different, and it is very important to distinguish the difference, so it is necessary to choose equations with clear short-term and long-term dynamics [6]. Al Mulali (2016) using the time period of 1980-2012, investigated the environmental Kuznets curve (EKC) hypothesis in the Kenyan. The results revealed that fossil fuel energy consumption, gross domestic product, urbanization, and trade openness increased air pollution mutually in the long-run and short-run [7].

Some scholars in China have also verified the EKC curve. For example, Wang Weiguo and Xia Yanqing studied the relationship between economic growth and environmental pollution in Liaoning Province, which found that the EKC curve in Liaoning Province is N-shaped [8]. Li Da and Wang Chunxiao used the simplified model to verify the relationship between economic growth and environmental pollution in 30 provinces of China from 1998 to 2004, which also concluded that the "inverted U-shaped" environment Kuznets curve does not exist [9]. Peng Shuijun analyzed the relationship between China's six categories of environmental pollution indicators and per capita GDP, and concluded that there is a mutual relationship between economic growth and environmental pollution [10]. Wang Huimin based on co-integration analysis and error correction model to study the long-term equilibrium and short-term dynamic adjustment relationship between economic growth and water environmental pollution in Jiangsu, Sichuan and Changzhou from 1992 to 2010 [11].

Although the relationship between economic growth and water pollution has been widely discussed, there are still some shortcomings. Most of the existing research mainly examines the relationship between economic growth and water pollution at the national or provincial level, ignoring regional differences within the provincial level, which will lead to bias. Therefore, according to the actual 
GDP in 2016, this paper first sorted 11 cities of Jiangxi Province from large to small, and then combined with the discharge of industrial wastewater which 11 cities were divided into three categories. The first category includes Nanchang City, Ganzhou City, Ji'an City, Yichun City, and Fuzhou City. The actual GDP of these five cities is ranked better than the ranking of water environment pollution. The second category includes Jiujiang City, Shangrao City, Jingdezhen City, and Yingtan City. The rankings of the actual GDP of these four cities are the same as the ranking of water environment pollution. The third category includes Xinyu City and Pingxiang City, as follow in Table 1. The actual GDP of these two cities is ranked inferior to the ranking of water pollution. In particular, Pingxiang City has the most significant contrast in the ranking of the two types of indicators. Based on this, a reasonable model is established to provide effective theoretical support for the sustainable development of cities in Jiangxi Province and the effective management of local environmental pollution.

\section{Model and Data Source}

\subsection{Model Pecification}

\subsubsection{EKC Hypothesis}

Regardless of other factors, only consider the impact of the simplest economic growth on water pollution, which test the environmental Kuznets curve, and establish the theoretical model as follows:

$$
y_{i, t}=\alpha_{i, 0}+\alpha_{i, 1} X_{i, t}+\alpha_{i}, 2 X_{i, t}^{2}+\varepsilon_{i, t}
$$

where $y$ is a water environmental pollution load indicator, $i$ and $t$ respectively represent different urban classifications and different years in Jiangxi Province, $\alpha_{0}, \alpha_{1}, \alpha_{2}$ is the coefficient vector, $x$ is the regional GDP, and $\varepsilon$ is the other variable that may cause the environment deterioration. Since the natural logarithmic transformation of time series data can eliminate the possible heteroscedasticity and does not change the nature and relationship of the data, the logarithmic form of the estimation model is as follows.

$$
\ln y_{i, t}=\beta_{i, 0}+\beta_{i, 1} \ln x_{i, t}+\beta_{i, 2} \ln x_{i, t}^{2}+\varepsilon_{i, t}
$$

If $\beta_{1}=\beta_{2}=0$, indicates a horizontal relationship. If $\beta_{1}<0, \beta_{2}=0$, represents a linear relationship of monotonically decreasing, if $\beta_{1}>0, \beta_{2}=0$, represents a linear relationship that is monotonically increasing. If it is $\beta_{1}<0, \beta_{2}>0$, it means a U-shaped relationship. If it is $\beta_{1}>0, \beta_{2}<0$, it means an inverted $U$-shaped relationship, that is, in the early stage of economic growth, environmental pollution is inevitable, but when the economy reaches a new level, environmental pollution will gradually improve.

\subsubsection{ADRL Model}

The autoregressive distribution lag model (ARDL) was first proposed by Charemza. It is refined and popularized by Pesaran [12]. Compared with the 
Table 1. Distribution of 11 cities in the Jiangxi Province.

\begin{tabular}{cccccc}
\hline Region & \multicolumn{3}{c}{ city } & & \\
\hline The first type & Nachang, & Ganzhou & Ji'an & Yichun & Fuzhou \\
The second type & Jiujiang & Shangrao & Jdzhen & Yingtan & \\
The third type & Xinyu & Pingxiang & & & \\
\hline
\end{tabular}

traditional method of cointegration test, the autoregressive distribution lag model, which based on the various advantages of VAR mode, requires that the monotonicity of each time series should not exceed 1 . Moreover, both the first-order and zero-order single-integer can be included in the model for analysis. At the same time, the estimation result of the ARDL method is more stable when the sample is small. Thirdly, the method overcomes problems of false regression caused by non-stationary time series data. The ARDL model for a single city can be expressed as:

$$
\begin{aligned}
\Delta \ln y_{t}= & b_{0}+\sum_{i=1}^{o} b_{1 j} \Delta \ln y_{t-j}+\sum_{i=1}^{p} b_{2 j} \Delta \ln x_{t-j}+\sum_{i=1}^{q} b_{3 j} \Delta \ln x_{t-i}^{2} \\
& +\delta_{1} \ln y_{t-1}+\delta_{2} \ln x_{t-1}+\delta_{3} \ln x_{t-1}^{2}+\mu_{t}
\end{aligned}
$$

where: $o, p, q$ represents the maximum lag order that is desirable, and $b_{\Phi j}(\Phi=1,2,3)$ is the short-term dynamic coefficient, which $\delta_{i}(i=1,2,3)$ is the long-term equalization coefficient.

The boundary test is based on the F statistic and the Wald statistic. The null hypothesis of the test is that there is no stable long-term relationship between the variables. That is, $H_{0}: \delta_{1}=\delta_{2}=\delta_{3}=0$. The alternative hypothesis is: $H_{1}: \delta_{1} \neq 0$ or $\delta_{2} \neq 0$ or $\delta_{3} \neq 0$. This hypothesis is judged by a joint significant $\mathrm{F}$ statistic. If the obtained $\mathrm{F}$ value is greater than the upper limit of the critical value, the original hypothesis is rejected, and there is a long-term cointegration relationship between the variables; if the $\mathrm{F}$ value is less than the upper limit of the critical value, the original hypothesis is not rejected, and there is no long-term cointegration relationship between the variables; When the $\mathrm{F}$ value is between the upper limit and the lower limit of the critical value, it is impossible to judge whether there is a cointegration relationship between the variables, and thus it is necessary to check the integration order of the variables.

Long-term elasticity and short-term elasticity can be further estimated if the boundary test is used to prove that all variables have a cointegration relationship of not more than $\mathrm{I}(1)$. Long-term elasticity is estimated by the ARDL $(o, p, q)$ model, and short-term elasticity is obtained by the ARDL-ECM model, as follows:

$$
\Delta \ln y_{t}=c_{0}+\sum_{i=1}^{o} c_{1 j} \Delta \ln y_{t-j}+\sum_{i=1}^{p} c_{2 j} \Delta \ln x_{t-j}+\sum_{i=1}^{q} c_{3 j} \Delta \ln x_{t-i}^{2}+\theta E C_{t-1}+\varepsilon_{t}
$$

\subsection{Indicator Selection and Data Processing}

The dataset of this paper is the observations data of Jiangxi Province from 1998 to 2016. All data are collected from the Jiangxi Statistical Yearbook (1999-2017). 
First, due to the change of pure price level does not mean an increase of output, in order to facilitate calculation and comparison, the economic indicators are based on the actual value of the regional GDP. Secondly, some indicators of water pollution have no long-term sample data. In view of the fact that industrial wastewater is one of the most important causes of urban water pollution, the water environmental load index selected in this paper is industrial wastewater discharge. In order to avoid the influence of the possible heteroscedasticity on the subsequent empirical analysis, all data were logarithmically processed.

\section{Empirical Analysis}

\subsection{Unit Root Test}

Generally speaking, most sequences of economic variables are non-stationary. If s non-stationary sequence is used to conduct a regression analysis, it would generate spurious regression. Therefore, we first test the robustness of the variables sequences. Although the boundary test does not need to verify the zero-order or first-order cointegration of each time series, the statistics of the boundary test may be biased if the second-order stationary sequence occurs,. In order to obtain a relatively stable result, the paper firstly conducted the unit root test of ADF and $\mathrm{PP}$, to ensure that the single order of each variable does not exceed 1 . The results are shown in Table 2.

The results obtained from the ADF test and the PP test in the above table are basically consistent, and both variables do not exceed I(2), so the ARDL model can be analyzed. Due to space limitations, the results of unit root test in the second and third categories of cities are not listed in one list, and the results are the same as those of the first type of cities, so co-integration analysis can be performed.

\subsection{Test Results of Long-Term Equilibrium between Economic Growth and Water Pollution}

\subsubsection{Cointegration Test Results of ARDL Model}

The ARDL model is used in Equation (3) to establish a long-term equilibrium relationship between variables, and the optimal lag period $(o, p, q)$ is selected based on the AIC and SBC methods. According to the margin test value given by Pesaran, the results of the long-term equilibrium relationship test are shown in Table 3.

Compared with the corresponding boundary values, The F-statistic in Table 2 shows that there is a linear relationship between the discharge of industrial wastewater and the regional GDP in the first type of cities. What's more, the elastic coefficient of the impact of economic growth on the water pollution is negative. The t-statistics is significant at the level of $5 \%$. The main reason can be found in the following two aspects. On the one hand, these cities have established many high-tech industrial parks in recent years, which actively introducing high-tech to improve the efficiency of clean energy. On the other hand, relying on the 
Table 2. Unit root test of water pollution and regional GDP in the first type of cities.

\begin{tabular}{cccccc}
\hline & \multicolumn{2}{c}{ ADF test } & \multicolumn{2}{c}{ pp test } & \\
\cline { 2 - 5 } variable & Level value & $\begin{array}{c}\text { First order } \\
\text { difference }\end{array}$ & Level value & $\begin{array}{c}\text { First order } \\
\text { difference }\end{array}$ & results \\
\hline $\ln y$ & -2.263 & $-4.024^{* *}$ & -2.36 & $-4.47^{*}$ & I (1) \\
$\ln x$ & -2.65 & $-2.23^{* * *}$ & -2.08 & $-2.25^{* *}$ & I (1) \\
$\ln x^{2}$ & -2.09 & $-2.19^{* *}$ & -3.21 & $-2.22^{*}$ & I (1) \\
\hline
\end{tabular}

Note: ${ }^{* *}$ indicates significant at $1 \%,{ }^{* *}$ indicates significant at $5 \%$, and ${ }^{*}$ indicates significant at $10 \%$.

Table 3. Long-term relationship coefficient estimated by ARDL model.

\begin{tabular}{ccccc}
\hline & Regression & Variable & $\begin{array}{c}\text { coefficient T } \\
\text { statistic }\end{array}$ & F statistic \\
\hline First class city & $\ln$ & -1.41 & 3.97 & $6.89^{* *}$ \\
Second class city & $\ln x$ & 2.14 & 6.85 & $11.32^{* * *}$ \\
\hline
\end{tabular}

Note: ${ }^{* *}$ indicates significant at $1 \%,{ }^{* *}$ indicates significant at $5 \%$, and ${ }^{*}$ indicates significant at $10 \%$.

traditional red resources, the tourism industry is vigorously developed and the added value of the tertiary industry is constantly increased. There is a quadratic curve relationship between the discharge of industrial wastewater and the regional GDP in the second class of cities. The relationship between the water pollution and the actual regional GDP of the third type of cities cannot be determined by the ARDL method.

\subsubsection{Cointegration Test Results for the Johansen Model}

For the first-order cointegration variables, the Johansen test can be used to test the long-term equilibrium relationship. The results are shown in Table 4. The results show that there is a long-term stable equilibrium relationship between lny, $\ln x$ and $(\ln x) 2$ in the cities of first, second and third categories. Based on the results of the BT test and the Johansen test, there is an inverted U-shaped EKC curve between industrial wastewater discharge and real GDP in the first and third types of cities. There is a linear relationship between the discharge of industrial wastewater and the actual regional GDP in the second class of cities.

\subsection{Test Results of Short-Term Dynamic Relationship between Economic Growth and Water Pollution}

There is a long-term stable relationship between the first kind of urban economic growth and the water environmental pollution variable. If the cointegration relationship is derived from the ARDL model, this paper uses the ARDL-ECM model to analyze the relationship between long-term equilibrium and short-term dynamic adjustment between variables. The results are shown in Table 5.

In the long-term equilibrium adjustment section, the parameters of the error correction term are all negative and statistically significant at the $1 \%$ significant 
level. It is indicated that the model has a stable correction ability from short-term fluctuation to long-term equilibrium. The parameter estimation of the long-term equilibrium error term of the first type of cities is -1.206 , which the value is negative, indicating that the system convergence will be adjusted towards equilibrium. In the short-term dynamic adjustment part, the parameter estimated value of the actual regional GDP in the current period is 0.461 . It is significant at the level of $5 \%$, indicating that the actual regional GDP has a significant positive impact on the water pollution. The actual GDP of the second type of cities in the current period has a negative impact on the water environment, but it is not significant. The lag period of the actual regional GDP has a significant positive impact on the water pollution.

If the cointegration relationship is derived by the Johansen method, the ECM model proposed by Engle and Granger is analyzed by using the short-term dynamic relationship between variables.

The results are shown in Table 6. A $1 \%$ increase in the actual regional GDP of the first type of cities, the industrial wastewater discharge will increased by $0.075 \%$. Forever, a $1 \%$ increase in the square of the actual regional GDP will result in an increase of $2.31 \%$ in emissions. That is to say, in the case of economic growth, water pollution has been suppressed to a certain extent, which is likely to be the result of responding to relevant policies. For example, enterprises with serious environmental pollution should be shut down for rectification. The normal production will not be allowed until the enterprise's sewage discharge reaches the corresponding discharge standards. A $1 \%$ increase in the square of the real GDP of the second category of cities, industrial wastewater discharge will increase by $1.465 \%$. That is to say, with the growth of economic aggregates, industrial wastewater discharge continues to rise. The main reason for this phenomenon is that the second type of cities are located in the inter-provincial borders, such as

Table 4. Johansen's cointegration test results between variables.

\begin{tabular}{cccccc}
\hline \multirow{2}{*}{ City } & \multirow{2}{*}{ Null hypothesis } & \multicolumn{2}{c}{ Trace test } & \multicolumn{2}{c}{ Characteristic root test } \\
\cline { 3 - 6 } & & Trace statistics & $\begin{array}{c}\text { Threshold } \\
\text { value (5\%) }\end{array}$ & $\begin{array}{c}\text { Characteristic } \\
\text { root statistic }\end{array}$ & $\begin{array}{c}\text { Threshold } \\
\text { value (5\%) }\end{array}$ \\
\hline \multirow{2}{*}{ First class } & none & 56.39 & $29.8^{* *}$ & 24.15 & $21.13^{* *}$ \\
& At least one & 32.24 & $15.5^{* *}$ & 21.89 & $14.26^{* *}$ \\
& At most two & 10.36 & $3.84^{* *}$ & 10.36 & $3.84^{* *}$ \\
\multirow{2}{*}{ Second class } & none & 36.48 & $29.8^{* *}$ & 23.43 & $21.13^{* *}$ \\
& At least one & 13.05 & 15.5 & 11.16 & 14.26 \\
& At most two & 1.89 & 3.84 & 1.89 & 3.84 \\
& none & 46.06 & $29.8^{* *}$ & 29.03 & $21.13^{* *}$ \\
Third class & At least one & 17.03 & $15.5^{* *}$ & 15.5 & $14.26^{* *}$ \\
& At most two & 1.52 & 3.84 & 1.52 & 3.84 \\
\hline
\end{tabular}

Note: ${ }^{* *}$ indicates significant at $1 \%,{ }^{* *}$ indicates significant at $5 \%$, and ${ }^{*}$ indicates significant at $10 \%$. 
Table 5. Long-term equilibrium and short-term dynamic adjustment relationship of ARDL model.

\begin{tabular}{ccccccc}
\hline Category & Model & $\Delta \ln x$ & $\Delta \ln x(-1)$ & $\Delta \ln x^{2}$ & $\Delta \ln x^{2}(-1)$ & $\operatorname{Ecm}(-1)$ \\
\hline First class city & ARDL (1.0) & $0.461^{* * *}$ & & & & $-1.206^{* *}$ \\
$\begin{array}{c}\text { Second class } \\
\text { city }\end{array}$ & ARDL (1.2) & -0.59 & $32.23^{*}$ & $3.148^{*}$ & -1.36 & $-1.83^{* * *}$ \\
\hline
\end{tabular}

Note: ${ }^{* *}$ indicates significant at $1 \%,{ }^{* *}$ indicates significant at $5 \%$, and ${ }^{*}$ indicates significant at $10 \%$.

Table 6. Short-term dynamic relationship based on ECM model.

\begin{tabular}{ccccc}
\hline Category & & $\Delta \ln y$ & $\Delta \ln x$ & $\Delta \ln x^{2}$ \\
\hline First class city & $\Delta \ln y$ & $0.092^{\star * \star}$ & $0.075^{\star}$ & $2.31^{\star}$ \\
Second class city & $\Delta \ln y$ & -0.029 & & $1.465^{\star}$ \\
\hline
\end{tabular}

Note: ${ }^{* *}$ indicates significant at $1 \%,{ }^{* *}$ indicates significant at $5 \%$, and ${ }^{\star}$ indicates significant at $10 \%$.

Jiujiang City lies at the junction of Jiangxi Province, Hubei Province, Anhui Province and Hunan Province. In order to shorten the gap with the first-class cities, the second-class cities have undertaken some high-pollution and high-consumption industries in developed areas of China, which has aggravated the water pollution of the second-class cities.

\subsection{Regional Analysis}

Based on the above empirical results, some interesting phenomena have emerged. First, there is an inverted "U" EKC curve between the industrial wastewater discharge and the actual regional GDP of the first type of cities, and there is a general tendency to approach the inflection point. The occasional negative correlation between economic growth and water pollution is not sufficient to show that Jiangxi's economic development has reached a high level and reached the "inflection point" in the inverted U-shaped of the environmental Kuznets curve. It can only show that the contradiction between environmental pollution and economic growth in the first type of cities has been somewhat eased. The reason is that as economic growth reaches and exceeds a certain threshold level, people's environmental awareness and environmental quality requirements have been improved, so as to accelerate the implement of a series of pollution reduction measures. Therefore, the industrial wastewater discharge has been effectively treated.

Secondly, the industrial wastewater discharge in the second type of cities has a linear relationship with the actual regional GDP, so the ideal trend has not been found. Characteristics of economic growth in the second category of cities, lead to environmental deterioration, then environmental pollution aggravation economic growth. Therefore, there is a spiral of rising between economic growth and environmental quality deterioration in the second type of cities. The main reason for this phenomenon is that with the development of China's economic level, the high-energy-consuming industries in economically developed areas have shifted to inland areas; then the second-class cities have undertaken some high-pollution 
and high-consumption types in the eastern coastal areas of China. So the kind of economic growth leads to environmental degradation and environmental degradation further promotes the cross-increasing relationship of economic growth.

The third finding is that the trend of industrial wastewater discharge and actual regional GDP in the third category is not ideal. For example, Pingxiang City has the highest industrial wastewater discharge in 2016, but the actual regional GDP is at the bottom. The leading industry of Pingxiang City is the iron and steel industry, which means that the traditional high-pollution and high-consumption industry has experienced the economic growth fatigue, which the resulting water environment pollution is difficult to be effectively solved.

\section{Conclusions}

This paper uses data from 1998 to 2016 to explore the relationship between long-term equilibrium and short-term dynamic adjustment of economic growth and water pollution in cities of Jiangxi Province. The results show that pollutant emissions do not automatically improve with the growth of economic aggregates. The difference in urbanization process and the difference of urban leading industries have different effects on the degradation of water environment quality. For the water pollution indicators with ideal trends, that is to say, the situation is that environmental pollution is contained in the case of economic growth, which is likely to be the result of responding to relevant policies. Therefore, while continuing to reduce industrial pollution emissions, we cannot ignore the consequences of domestic sewage discharge to environmental pressure. For water pollution indicators that fail to show ideal trends, we must actively increase pollution control and adjust the industrial structure. For example, Jingdezhen is known as the "Ceramic Capital" both at home and abroad. Improving the "burning porcelain" can not only promote economic growth, but also reduce environmental pollution, so as to reach the turning point of EKC as soon as possible.

Of course, there are still some issues that are worth discussing. For example, the data set used in this study is only 19 years. In the past 19 years, Jiangxi Province may be in a real long-term transition zone of EKC relationship. In this case, a larger data set will capture the real long-term influence. Therefore, it is necessary to expand the data set in the future. In addition, as a central province, Jiangxi Province itself is slow in introducing advanced technology and utilizing advanced technology efficiency. Therefore, this article does not consider technical factors. However, as time goes by, it is possible to greatly promote advanced and clean energy technologies and consider more accurate technological changes. Meantime, this is one of the future directions.

In summary, due to geographical location, environmental resources and the economic development of the cities in Jiangxi Province, the water pollution condition is different. Each city should build the characteristic industry based on its own unique resources and formulate effective environmental pollution policy to 
alleviate water pollution, so as to achieve the harmonious development of human being and nature.

\section{Acknowledgements}

This article is supported by the science and technology project of Jiangxi Provincial Education Commission, "Study on the Combining Efficiency of Agricultural Science and Technology with Finance in Jiangxi” (Project No. GJJ151514) and the Humanities and Social Sciences project of Universities in Jiangxi Province, "Study on Jiangxi's Energy Efficiency and Its Spatio-temporal Variation Based on DEA-ESDA" (Project No. JC162015).

\section{Conflicts of Interest}

The authors declare no conflicts of interest regarding the publication of this paper.

\section{References}

[1] Fan, Y. (2018) Empirical Analysis on a Two-Way Relationship between Economic Growth and Environmental Pollution of 285 Cities in China. Environmental Science Survey, 37, 1-5.

[2] Ruan, L.N. and Yang, S.B. (2010) Analysis on the Employment Effect of the Third Industry Based on Panel Data Model-Taking Jiangxi Province as an Example. Statistics and Decision Making, 21, 92-94.

[3] Grossman, G. and Krueger, A. (1991) Environmental Impacts of a North American Free Trade Agreement. National Bureau of Economic Research Working Paper.

[4] Panayotou, T., Peterson, A. and Sachs, J. (2000) Is the Environmental Kuznets Curve Driven by Structural Change? What Extended Time Series May Imply for Developing Countries. Harvard Institute for International Development, No. 80.

[5] Dijkgraaf, E. and Vollebergh, H.R.J. (2005) A Test for Parameter Homogeneity in $\mathrm{CO}_{2}$ Panel EKC Estimations. Environmental \& Resource Economics, 32, 229-239. https://doi.org/10.1007/s10640-005-2776-0

[6] Egli, H. (2014) The Environmental Kuznets Curve-Evidence from Time Series Data for Germany. WIF Institute for Economic Research, Working Paper. http://www.cer.ethz.ch/research/wp_03_28.pdf

[7] Al-Mulali, U., Solarin, S.A. and Ozturk, I. (2016) Investigating the Presence of the Environmental Kuznets Curve (EKC) Hypothesis in Kenya: An Autoregressive Distributed Lag (ARDL) Approach. Natural Hazards, 80, 1729-1747. https://doi.org/10.1007/s11069-015-2050-x

[8] Wang, W.G. and Xia, Y.Q. (2007) Study on the Relationship between Economic Growth and Environmental Pollution in Liaoning Province. Social Science Journal, 1, 103-107.

[9] Li, D. and Wang, C.X. (2007) The Relationship between China's Economic Growth and the Emission of Air Pollutants-Based on the Empirical Study of Panel Data in Different Provinces. Science of Finance and Economics, 2, 43-50.

[10] Peng, S.J. and Bao, Q. (2006) China's Economic Growth and Environmental Pollution-Empirical Research Based on Generalized Impulse Response Function Method. Journal of Chinese Industrial Economy, 5, 15-23. 
[11] Wang, H.M. and Fu, T. (2014) Economic Growth and Water Pollution in Suzhou, Wuxi and Changzhou. Soft Science, 1, 91-94.

[12] Pesaran, M.H., Shin, Y. and Smith, R. (2001) Bounds Testing Approaches to the Analysis of Level Relationships. Journal of Applied Econometrics, 16, 289-326.

https://doi.org/10.1002/jae.616 